\title{
Influence of Preparation Processes on the Resistivity of Porous Ti Based ATO
}

\author{
Lan Wang, Fanrong Pan, Yupei Zhao, Longyao Wang*
}

Key Laboratory of Biomass Energy and Material, Jiangsu Province, Catalysis and Green

Manufacturing Collaborative Innovation Center, Changzhou University, Changzhou 213164, China

*E-mail: w.longyao@gmail.com

doi: $10.20964 / 2016.07 .73$

Received: 18 April 2016 / Accepted: 25 May 2016 / Published: 4 June 2016

In order to avoid the mud cracks and decrease the resistivity, the ATO (antimony doped tin oxide) coating on $\mathrm{Ti}$ substrate is prepared by thermal decomposition method. The ATO coating was characterized and the preparation conditions were optimized. In the experiments, the sintering temperature and holding time both can promote the oxidization of the substrate Ti. Although the resistivity of ATO is higher than that of Ti, ATO coating can protect the substrate Ti from passivation. In this case, both uneven and excess thickness of the coating coverage will lead the resistivity increase. The results indicate that the Ti based ATO shows low resistivity with uniform and compact surface under the optimized experiment conditions ( Sb doping content 15\%wt, coating 20 times and sintering in $450{ }^{\circ} \mathrm{C}$ for $15 \mathrm{~min}$ ).

Keywords: porous titanium; ATO; resistivity; preparation

\section{FULL TEXT}

(C) 2016 The Authors. Published by ESG (www.electrochemsci.org). This article is an open access article distributed under the terms and conditions of the Creative Commons Attribution license (http://creativecommons.org/licenses/by/4.0/). 